\title{
T790M Correlates with Longer Progression-free Survival in Non-small Cell Lung Carcinomas Harboring EGFR Mutations
}

\author{
YOSHIHITO KOGURE*, FUMIE SHIGEMATSU*, MASAHIDE OKI and HIDEO SAKA \\ Department of Respiratory Medicine, National Hospital Organization Nagoya Medical Center, Nagoya, Japan
}

\begin{abstract}
Background/Aim: The aim of this study was to evaluate the relationship between T790M status and the characteristics of non-small cell lung cancer (NSCLC) patients undergoing rebiopsy after initial epidermal growth factor receptor-tyrosine kinase inhibitor (EGFR-TKI) therapy and whether the site of rebiopsy has an effect on the detection rate for T790M in these patients. Materials and Methods: We retrospectively reviewed the clinical data from stage IV or recurrent NSCLC patients who harbored EGFR mutations and who had initially received EGFR-TKI at our Center from January 2009 to December 2016. Results: Overall, 129 patients were included. The median age at EGFR-TKI therapy initiation was 73 years and 110 showed progressive disease. The presence of T790M mutation was associated with significantly longer progression-free survival (PFS) and EGFR mutation status. The participants' characteristics and rebiopsy site did not affect the T790M detection rate. Conclusion: It is highly recommended that patients with exon 19 deletions and long PFS undergo screening for T790M.
\end{abstract}

Worldwide, lung cancer is the most common cancer associated with mortality, and non-small cell lung cancer (NSCLC) is its most prevalent type. With developments in chemotherapy, the overall survival of patients with NSCLC has improved; however, the use of chemotherapy is limited. In 2004, mutations of epidermal growth factor receptor $(E G F R)$ were discovered in some NSCLCs. It was also reported that NSCLCs harboring EGFR mutations responded well to treatment with EGFR tyrosine kinase inhibitors

This article is freely accessible online.

*These Authors contributed equally to this study.

Correspondence to: Yoshihito Kogure, Department of Respiratory Medicine, National Hospital Organization Nagoya Medical Center, 4-1-1, Sannomaru, Naka-ku, Nagoya 460-0001, Japan. Tel: +81 529511111, Fax: +81 529713334, e-mail: yo-kogure@umin.ac.jp

Key Words: EGFR mutation, T790M, non-small cell lung carcinoma, rebiopsy.
(EGFR-TKIs) (1, 2). EGFR mutations are frequently observed in Asian women who have adenocarcinoma and have never smoked (3). Approximately $45 \%$ of Japanese patients with lung adenocarcinoma had EGFR mutations (4). However, most of these patients had a relapse after EGFRTKI therapy due to acquired resistance. T790M is a major acquired resistant mutation in NSCLCs with EGFR mutations. It was detected in 53\%-62\% of the rebiopsy specimens obtained from patients with acquired resistance after EGFR-TKI treatment (5-7). Overcoming this resistance is crucial in improving the survival of patients with EGFR mutations after the failure of initial EGFR-TKI therapy.

Afatinib is an irreversible ErB-family blocker which has shown preclinical activity against the T790M mutation (8). However, LUX-Lung 4 (9) demonstrated modest afatinib activity with a progression-free survival (PFS) of 4.4 months and an objective response rate of $8.2 \%$ in patients whose disease progressed during the administration of erlotinib and/or gefitinib.

Osimertinib is a third-generation irreversible EGFR-TKI that is both EGFR mutation- and T790M mutation-selective. In AURA 3 (10), it was observed that osimertinib had a significantly greater efficacy than platinum plus pemetrexed in patients with T790M-positive NSCLC in whom the disease had progressed during first-line EGFR-TKI therapy. In Japan, osimertinib is now available for T790M-positive patients after disease progression during initial EGFR-TKI therapy, and rebiopsy was to be performed to detect T790M in these patients.

This study evaluated the relationship between T790M status and the characteristics of patients undergoing rebiopsy after initial EGFR-TKI therapy.

\section{Patients and Methods}

Study participants. Data were extracted retrospectively from patients' medical records at the National Hospital Organization Nagoya Medical Center (Nagoya, Japan). The chosen patients had NSCLC stage IIB-IV or recurrent NSCLC, had active EGFR mutations, had an Eastern Cooperative Oncology Group (ECOG) performance status (PS) of 0-4, and received initial EGFR-TKI treatment at our institute. Patients with de novo T790M mutations 
were excluded. The study was approved by the institutional review board of Nagoya Medical Center on November 2, 2017 (approval number: 2017-61). Written informed consent for the testing of EGFR mutations, detection of T790M mutation, and performance of rebiopsy was obtained from each patient.

EGFR mutation analysis. Every specimen was analyzed using the cobas ${ }^{\circledR}$ EGFR Mutation Test v2, obtained from Roche Diagnostics (Indianapolis, IN, USA), with real-time polymerase chain reactions to detect mutations in exons $18-21$ of the EGFR gene according to the manufacturer's instructions.

Data collection. The study was conducted between January 2009 and December 2016. Progressive disease (PD) was defined as the presence of tumor growth, as measured through imaging based on the Response Evaluation Criteria in Solid Tumors version 1.1 (11) or as a worsening of clinical symptoms.

We collected data on patients' characteristics, clinical course, initial site of recurrence after treatment with EGFR-TKI, and the T790M status of the patients undergoing rebiopsy, which was defined as biopsy performed to detect T790M after the failure of the initial EGFR-TKI treatment. The rebiopsy sites were also analyzed.

Statistical analysis. Analyses were conducted using PASW Statistics 21.0 (SPSS Inc., Chicago, IL). Chi-square and Fisher's exact tests were used to assess the correlation between patients' characteristics and T790M status, and between the rebiopsy site and T790M status. A Mann-Whitney $U$-test was used to assess the correlation between the median period from the time of EGFR-TKI therapy failure to the first rebiopsy and T790M status, and between the median number of times a biopsy was performed and T790M status. The PFS was calculated from the date of the initiation of EGFR-TKI therapy to the date of progression; this was assessed using the Kaplan-Meier method and compared using a log-rank test. Differences with a $p$-value $<0.05$ were considered statistically significant.

\section{Results}

Patients' characteristics. Between January 2009 and December 2016, 129 patients received EGFR-TKI treatment at our institute; the characteristics of these patients are shown in Table I. The cohort comprised $81(67 \%)$ women, with a median age of 73 years (range $=38-97$ years). All patients were Asian. A total of 104 patients $(81 \%)$ had an ECOG PS of $0-1$; most patients (128 patients, 99\%) had adenocarcinoma, and two-thirds of them had stage IV disease. The proportion of patients harboring the exon 19 deletion (19 del) was similar to that of patients with the point mutation in exon 21 (L858R). Two patients were excluded as they had de novo T790M mutations, and 1 patient was excluded because of missing data. The number of patients with PD was 110 , and 42 (38\%) of them underwent rebiopsy (Figure 1). The others did not undergo rebiopsy due to deterioration of their general condition, treatment policy of best supportive care, and inability to biopsy the progressive lesion. Rebiopsy was performed 50 times in 42 patients, with
Table I. Patients' characteristics during the initial EGFR-TKI therapy $(n=129)$.

\begin{tabular}{|c|c|}
\hline Characteristic & No. \\
\hline Median age, years (range) & $73(38-97)$ \\
\hline \multicolumn{2}{|l|}{ Gender } \\
\hline Male & 48 \\
\hline Female & 81 \\
\hline \multicolumn{2}{|l|}{ ECOG PS } \\
\hline 0 & 55 \\
\hline 1 & 49 \\
\hline 2 & 12 \\
\hline 3 & 10 \\
\hline 4 & 1 \\
\hline NA & 2 \\
\hline \multicolumn{2}{|l|}{ Stage } \\
\hline IIB & 1 \\
\hline IIIA & 3 \\
\hline IIIB & 7 \\
\hline IV & 96 \\
\hline Recurrence after surgery & 23 \\
\hline \multicolumn{2}{|l|}{ Histological type } \\
\hline Adeno & 128 \\
\hline Squamous & 1 \\
\hline \multicolumn{2}{|l|}{$E G F R$ mutation type } \\
\hline Exon 19 deletion & 63 \\
\hline L858R & 59 \\
\hline Others & 7 \\
\hline \multicolumn{2}{|l|}{ EGFR-TKI } \\
\hline Gefitinib & 109 \\
\hline Erlotinib & 13 \\
\hline Erlotinib + Bevacizumab & 3 \\
\hline Afatinib & 4 \\
\hline
\end{tabular}

EGFR: Epidermal growth factor receptor; TKI: tyrosine kinase inhibitor; ECOG: Eastern Cooperative Oncology Group; NA: not applicable; PS: performance status. a median of 1 time (range $=1-3$ times). T790M-positivity was observed in 20 patients from 20 biopsies and T790Mnegativity was observed in 17 patients from 22 biopsies. Five patients had a pathologically negative status (Figure 1).

Progressive lesions. Primary lesions were the most commonly observed in sites with PD, followed by the bone, sites of pulmonary metastasis, and the brain (Figure 2). The numbers of patients showing disease progression in the bone and brain, which are difficult sites to biopsy, were 25 and 11, respectively. Bone and/or brain progression was observed in 25 patients, and biopsies were performed on 3 of them.

Patients who underwent rebiopsy. Of the 42 patients who underwent rebiopsy, 20 had T790M mutations, of whom 18 received osimertinib. The T790M-positive group had a significantly higher number of 19 dels than the T790Mnegative group ( $p=0.0016$, Table II), and thrice as many 19 


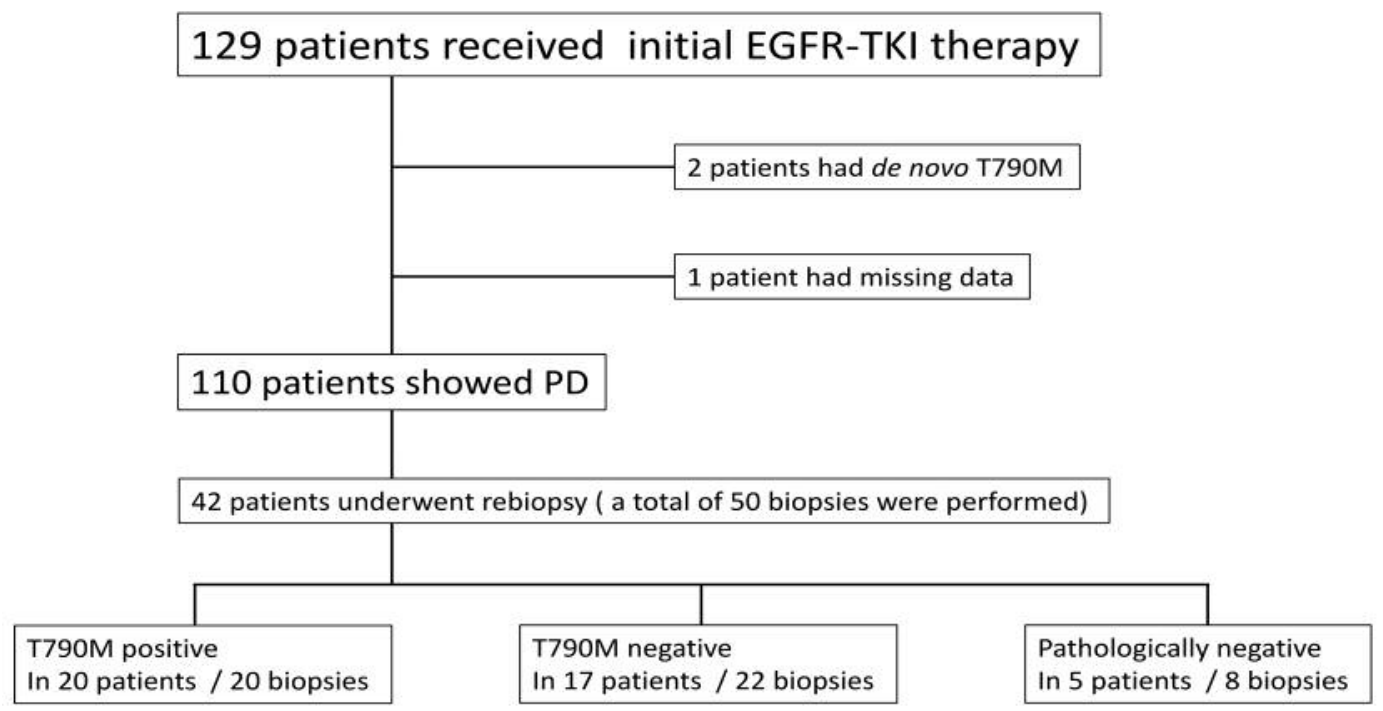

Figure 1. Flow chart of the study procedure. PD: Progressive disease; EGFR-TKI: epidermal growth factor receptor-tyrosine kinase inhibitor.

dels as those with L858R mutations. Patients' characteristics such as sex, smoking status, proportion of stage IV disease, time between EGFR-TKI therapy failure and first rebiopsy, and the number of biopsies did not affect the T790M status in the rebiopsies (Table II). T790M mutations were detected in 3 patients after the second rebiopsy, 4, 11, and 19 months after the first one.

T790M status and PFS after the initial EGFR-TKI treatment. T790M-positive patients showed a significantly longer PFS than the T790M-negative patients (527 [range $=321-733$ days] vs. 230 [range $=132-328$ days] days, $p=0.007$ ), as shown in Figure 3.

T790M status and rebiopsy site. In terms of the rebiopsy site, the most common site was the primary lesion (19 times, $38 \%$ ) followed by pleural effusion (6 times, 12\%). The correlation between the rebiopsy site and T790M status was reviewed. As shown in Figure 4, the proportion of T790M mutations in the same site as that of the initial biopsy was not significantly different from other sites (38\% vs. $57 \%$, $p=0.217$ ). The rebiopsy site, whether intra-thoracic or not, did not result in a significant difference in the proportion of T790M mutations (45\% vs. $54 \%, p=0.588)$.

\section{Discussion}

Currently, osimertinib is available for patients with EGFR mutations after disease progression during EGFR-TKI therapy. Therefore, the performance of a rebiopsy is important in detecting T970M mutations in those patients. Ideally,

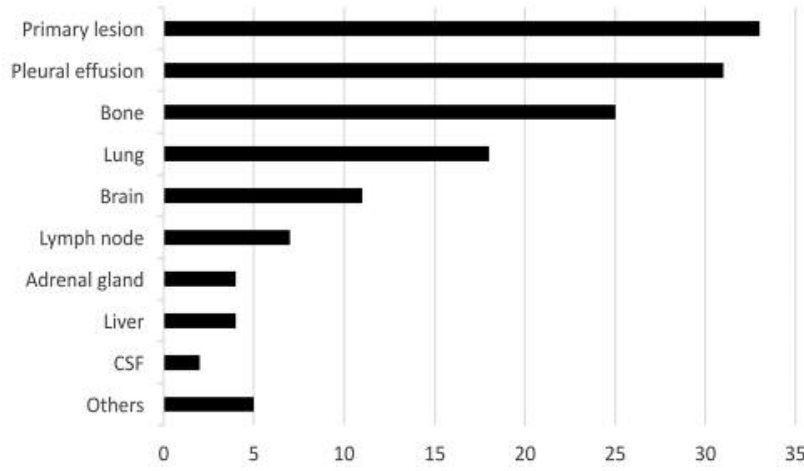

Figure 2. Number of progressive lesions in PD cases after initial EGFRTKI therapy. CSF: Cerebrospinal fluid; PD: progressive disease; EGFR: epidermal growth factor receptor; TKI: tyrosine kinase inhibitor. "Others" include the kidney, spleen, skin, ascites, and thyroid gland.

rebiopsy should be performed in all such patients; however, it is feasible in only $68-82 \%$ of cases (12). It stands to reason to perform the rebiopsy from the site that will provide the higher probability of detecting the T790M mutation. However, it was found that the rebiopsy site did not influence the T790M status, which is in line with the findings in a previous study by Tseng et al. (6). Thus, persisting on a specific site for rebiopsy might not be warranted.

Furthermore, Li et al. (7) and Hata et al. (13) showed that the T790M status did not correlate with patients' characteristics such as sex, smoking status, proportion of stage IV disease, time between EGFR-TKI therapy failure 
Table II. Patients' characteristics and T790M status.

\begin{tabular}{|c|c|c|c|}
\hline & $\mathrm{T} 790 \mathrm{M}+(\mathrm{n}=20)$ & $\mathrm{T} 790 \mathrm{M}-(\mathrm{n}=22)$ & $p$-Value \\
\hline Gender & & & 1 \\
\hline Male & 6 & 7 & \\
\hline Female & 14 & 15 & \\
\hline Smoking status & & & 0.76 \\
\hline Former/current & 7 & 9 & \\
\hline Never & 13 & 13 & \\
\hline EGFR mutation type & & & 0.0016 \\
\hline Exon 19 deletion & 15 & 5 & \\
\hline L858R & 5 & 16 & \\
\hline Others & 0 & 1 & \\
\hline Median period between EGFR-TKI failure and the 1st rebiopsy (days) (range) & $197(0-1322)$ & $181(0-657)$ & 0.50 \\
\hline Median number of times biopsy was performed (range) & $1(1-2)$ & $1(1-3)$ & 1 \\
\hline
\end{tabular}

EGFR: Epidermal growth factor receptor; TKI: tyrosine kinase inhibitor.

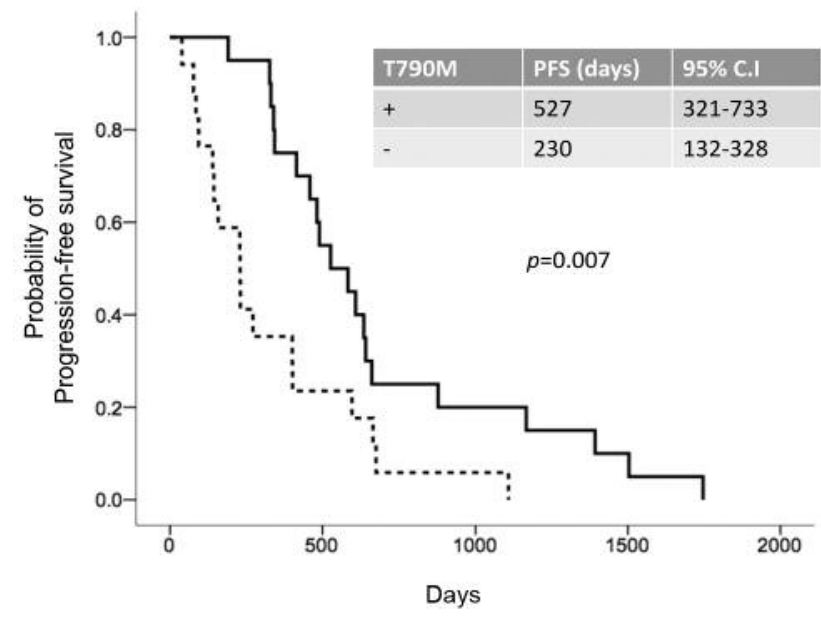

Figure 3. Progression-free survival after initial EGFR-TKI therapy, based on the T790M status.

and first rebiopsy, and number of biopsies. Similarly, no correlations between patients' characteristics and T790M status were observed.

T790M mutations were detected in $53-62 \%$ of the specimens obtained by rebiopsy from patients who acquired resistance after EGFR-TKI treatment (5-7); this is in agreement with our data in that T790M mutations were observed in $54 \%$ of patients in whom rebiopsy was performed.

Hata et al. reported that the prevalence of T790M mutations was higher among patients with 19 dels and acquired resistance to EGFR-TKI (19 dels 40\%, L858R 24\%); however, the difference was not significant ( $p=0.3343$ ) (11). Tseng et al. also described that 19 dels and L858R accounted for 59.2\% and $36.7 \%$ of all mutations in patients with emerging T790M

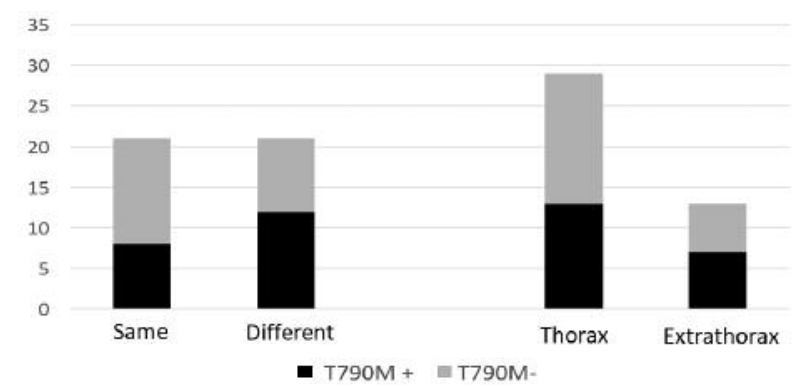

Figure 4. Association between rebiopsy site and T790M status.

mutations, respectively (6). In AURA trials, the major type of EGFR mutation was 19 del, which accounted for $62-68 \%$ of all EGFR mutations $(13,14)$. Our study showed that the number of patients with 19 dels (75\%) significantly outnumbered that of those with the L858R mutation among T790M-positive patients; this result is similar to those observed in previous trials. Thus, 19 del mutations may be more readily detected, regardless of the efficacy of EGFR-TKI.

With regards to the initial EGFR-TKI treatment, we found that T790M-positive patients had a significantly longer PFS than T790M-negative patients (527 days vs. 230 days, $p=0.007)$. This is consistent with the results obtained by Gaut et al. (15) who showed that T790M-positive patients on first-line treatment had a significantly longer PFS than T790M-negative patients (12.0 months vs. 9.0 months, $p=0.021)$. In addition, T790M-positive patients have also been reported to have long post-progression survival $(5,12)$.

Regarding biopsy timing and T790M status, Tseng et al. reported that there was no association between T790M status 
and rebiopsy timing (6). However, Graziano et al. (16) and Hata et al. (17) reported that the T790M status varied based on the biopsy site within the same patient. In this study, 3 patients showed temporal heterogeneity of T790M mutations in the second rebiopsy.

Our study has certain limitations. First, since it was a single-center retrospective study, the number of patients and biopsies performed was small, leading to a possibility of bias. Since the rebiopsy rate was low in the current study, comparisons with the findings of previous studies $(18,19)$ may not yield an accurate picture of differences between the T790M-positive and- negative groups. Second, rebiopsies could not be performed for all the lesions, especially those of the bone and brain, which were difficult to obtain. Third, although some of the included patients received EGFR-TKI as first-line therapy, others received it as second- or thirdline treatment. The therapies used before that may have affected the results in those patients. Fourth, the rebiopsy timings varied considerably, based on physicians' decisions.

\section{Conclusion}

In conclusion, among NSCLC patients treated with EGFRTKI, those with T790M mutations were found to frequently also show 19 dels, compared to T790M-negative patients. In addition, T790M-positive patients had a longer PFS. Therefore, screening these patients for T790M mutations may help in improving survival.

The T790M status did not correlate with the rebiopsy site; however, in the second rebiopsy, we observed temporal heterogeneity of the T790M mutations. Thus, there might be no point in persisting on a specific site for rebiopsy. Second rebiopsy could be considered when the first rebiopsy reveals T790M-negativity.

\section{References}

1 Lynch TJ, Bell DW, Sordella R, Gurubhagavatula S, Okimoto RA, Brannigan BW, Harris PL, Haserlat SM, Supko JG, Haluska FG, Louis DN, Christiani DC, Settleman J and Haber DA: Activating mutations in the epidermal growth factor receptor underlying responsiveness of non-small-cell lung cancer to gefitinib. N Engl J Med 350: 2129-2139, 2004.

2 Paez JG, Jänne PA, Lee JC, Tracy S, Greulich H, Gabriel S, Herman P, Kaye FJ, Lindeman N, Boggon TJ, Naoki K, Sasaki H, Fujii Y, Eck MJ, Sellers WR, Johnson BE and Meyerson M: EGFR mutations in lung cancer: correlation with clinical response to gefitinib therapy. Science 304: 1497-1500, 2004.

3 Mitsudomi T and Yatabe Y: Mutations of the epidermal growth factor receptor gene and related genes as determinants of epidermal growth factor receptor tyrosine kinase inhibitors sensitivity in lung cancer. Cancer Sci 98: 1817-1824, 2007.

4 Midha A, Dearden S and McCormack R: EGFR mutation incidence in non-small-cell lung cancer of adenocarcinoma histology: a systematic review and global map by ethnicity (mutMapII). Am J Cancer Res 5: 2892-2911, 2015.
5 Oxnard GR, Arcila ME, Sima CS, Riely GJ, Chmielecki J, Kris MG, Pao W, Ladanyi M and Miller VA: Acquired resistance to EGFR tyrosine kinase inhibitors in EGFR-mutant lung cancer: distinct natural history of patients with tumors harboring the T790M mutation. Clin Cancer Res 17: 1616-1622, 2011.

6 Tseng JS, Su KY, Yang TY, Chen KC, Hsu KH, Chen HY, Tsai CR, Yu SL and Chang GC: The emergence of T790M mutation in EGFR-mutant lung adenocarcinoma patients having a history of acquired resistance to EGFR-TKI: focus on rebiopsy timing and long-term existence of T790M. Oncotarget 7: 48059-48069, 2016.

7 Li W, Ren S, Li J, Li A, Fan L, Li X, Zhao C, He Y, Gao G, Chen X, Li S, Shi J, Zhou C, Fei K and Schmid-Bindert G: T790M mutation is associated with better efficacy of treatment beyond progression with EGFR-TKI in advanced NSCLC patients. Lung Cancer 84: 295-300, 2014.

8 Li D, Ambrogio L, Shimamura T, Kubo S, Takahashi M, Chirieac LR, Padera RF, Shapiro GI, Baum A, Himmelsbach F, Rettig WJ, Meyerson M, Solca F, Greulich H and Wong KK: BIBW2992, an irreversible EGFR/HER2 inhibitor highly effective in preclinical lung cancer models. Oncogene 27: 47024711,2008

9 Katakami N, Atagi S, Goto $\mathrm{G}$, Hida $\mathrm{T}$, Horai $\mathrm{T}$, Inoue A, Ichinose Y, Koboyashi K, Takeda K, Kiura K, Nishio K, Seki Y, Ebisawa R, Shahidi M and Yamamoto N: LUX-Lung 4: a phase II trial of afatinib in patients with advanced non-small-cell lung cancer who progressed during prior treatment with erlotinib, gefitinib, or both. J Clin Oncol 31: 3335-3341, 2013.

10 Mok TS, Wu YL, Ahn MJ, Garassino MC, Kim HR, Ramalingam SS, Shepherd FA, He Y, Akamatsu H, Theelen WSME, Lee CK, Sebastian M, Templeton A, Mann H, Marotti M, Ghiorghiu S, Papadimitrakopoulou VA and AURA3 Investigators: Osimertinib or platinum-Pemetrexed in EGFR T790M-positive lung cancer. N Engl J Med 376: 629-640, 2017.

11 Eisenhauer EA, Therasse P, Bogaerts J, Schwartz LH, Sargent D, Ford R, Dancey J, Arbuck S, Gwyther S, Mooney M, Rubinstein L, Shankar L, Dodd L, Kaplan R, Lacombe D and Verweij J: New response evaluation criteria in solid tumours: revised RECIST guideline (version 1.1). Eur J Cancer 45: 228-247, 2009.

12 Uozu S, Imaizumi K, Yamaguchi T, Goto Y, Kawada K, Minezawa T, Okamura T, Akao K, Hayashi M, Isogai S, Okazawa M, Hashimoto N and Hasegawa Y: Feasibility of tissue re-biopsy in non-small cell lung cancers resistant to previous epidermal growth factor receptor tyrosine kinase inhibitor therapies. BMC Pulm Med 17: 175, 2017.

13 Hata A, Katakami N, Yoshioka H, Takeshita J, Tanaka K, Nanjo S, Fujita S, Kaji R, Imai Y, Monden K, Matsumoto T, Nagata K, Otsuka K, Tachikawa R, Tomii K, Kunimasa K, Iwasaku M, Nishiyama A, Ishida T and Nishimura Y: Rebiopsy of non-small cell lung cancer patients with acquired resistance to epidermal growth factor receptor-tyrosine kinase inhibitor: Comparison between T790M mutation-positive and mutation-negative populations. Cancer 119: 4325-4332, 2013.

14 Goss G, Tsai CM, Shepherd FA, Bazhenova L, Lee JS, Chang GC, Crino L, Satouchi M, Chu Q, Hida T, Han JY, Juan O, Dunphy F, Nishio M, Kang JH, Majem M, Mann H, Cantarini M, Ghiorghiu S and Mitsudomi T: Osimertinib for pretreated EGFR Thr790Met-positive advanced non-small-cell lung cancer (AURA2): a multicentre, open-label, single-arm, phase 2 study. Lancet Oncol 17: 1643-1652, 2016. 
15 Gaut D, Sim MA, Yue Y, Wolf BR, Abarca PA, Carroll JM, Goldman JW and Garon EB: Clinical implications of the T790M mutation in disease characteristics and treatment response in patients with epidermal growth factor receptor (EGFR)-mutated non-small-cell lung cancer (NSCLC). Clin Lung Cancer 19: e19e28, 2019

16 Graziano P, de Marinis F, Gori B, Gasbarra R, Migliorino R, De Santis S, Pelosi G and Leone A: EGFR-driven behavior and intrapatient T790M mutation heterogeneity of non-small-cell carcinoma with squamous histology. J Clin Oncol 33: e115-118, 2015.

17 Hata A, Katakami N, Yoshioka H, Kaji R, Masago K, Fujita S, Imai Y, Nishiyama A, Ishida T, Nishimura Y and Yatabe Y: Spatiotemporal T790M heterogeneity in individual patients with EGFR-mutant non-small-cell lung cancer after acquired resistance to EGFR-TKI. J Thorac Oncol 10: 1553-1559, 2015.
18 Chouaid C, Dujon C, Do P, Monnet I, Madroszyk A, Le Caer H, Auliac JB, Berard H, Thomas P, Lena H, Robinet G, Baize N, Bizieux-Thaminy A, Fraboulet G, Locher C, Le Treut J, Hominal $\mathrm{S}$ and Vergnenegre A: Feasibility and clinical impact of rebiopsy in advanced non-small-cell lung cancer: a prospective multicenter study in a real-world setting (GFPC study 12-01). Lung Cancer 86: 170-173, 2014.

19 Arcila ME, Oxnard GR, Nafa K, Riely GJ, Solomon SB, Zakowski MF, Kris MG, Pao W, Miller VA and Ladanyi M: Rebiopsy of lung cancer patients with acquired resistance to EGFR inhibitors and enhanced detection of the T790M mutation using a locked nucleic acid-based assay. Clin Cancer Res 17: 1169-1180, 2011.

Received May 14, 2018

Revised June 19, 2018

Accepted June 20, 2018 